\title{
Aerosolization and Fluid Spillage During Phacoemulsification in Human Subjects
}

This article was published in the following Dove Press journal:

Clinical Ophthalmology

Jasper Ka Wai Wong (iD'

Jeremy Sze Wai John Kwok' Jonathan Cheuk Hung Chan' Kendrick Co Shih'

Renyuan Qin ${ }^{2}$

Denvid Lau ${ }^{2}$

Jimmy Shiu Ming Lai ${ }^{1}$

'Department of Ophthalmology, Li Ka Shing Faculty of Medicine, University of Hong Kong, Hong Kong; ${ }^{2}$ Department of Architecture and Civil Engineering, College of Engineering, City University of Hong Kong, Hong Kong
Correspondence: Jimmy Shiu Ming Lai Department of Ophthalmology, Li Ka Shing Faculty of Medicine, University of Hong Kong, Room 30I, Block B, Cyberport 4, 100 Cyberport Road, Hong Kong

Tel +8523962। 405

Email smjlai@netvigator.com
Background: Concerns had been raised for the potential hazard of SARS-CoV-2 transmissions via aerosols and fluid droplets during cataract surgeries amid the COVID-19 pandemic. This study aims to evaluate the rate of visible aerosol generation and fluid spillage from surgical wounds during phacoemulsification in human subjects.

Methods: This is a prospective consecutive interventional case series. High-resolution video captures of 30 consecutive uncomplicated phacoemulsification surgeries, performed by 3 board-certified specialists in ophthalmology, were assessed by 2 independent and masked investigators for intraoperative aerosolization and fluid spillage. Water-contact indicator tape was mounted on the base of the operating microscope, around the objective lens, to detect any fluid contact.

Results: No visible intraoperative aerosolization was detected in any of the cases, irrespective of different surgical practices among the surgeons with regard to wound size and position, lens fragmentation technique, power settings and means of ocular lubrication, or the different densities of cataract encountered. Large droplets spillage was noted from the paracentesis wounds in $70 \%$ of the cases. For all cases where fluid spill was detected on video, there was no fluid contact detected on the water-contact indicator tape.

Conclusion: Visible aerosolization was not detected during phacoemulsification in our case series. Although the rate of fluid spillage was high, the lack of detectable contact with the indicator tape suggested that these large droplets posed no significant infectious risks to members of the surgical team.

Keywords: phacoemulsification, aerosols, aerosolization, droplets, COVID

\section{Background}

The COVID-19 pandemic has affected all aspects of our life. Other than our usual daily activities and work schedules, many non-urgent medical services have been limited, or even suspended, to minimize risks of hospital and community transmission. However, the pandemic has now lasted for more than 10 months since the initial outbreak in Wuhan, China. There are still no signs of global resolution. As of early December 2020, the pandemic had affected 218 countries with more than 50 million patients and caused more than 1.3 million deaths. ${ }^{1}$

As one of the public eye centers in Hong Kong, a suspension of non-urgent ophthalmic services and elective surgery is not feasible due to high demand and long waiting times. ${ }^{2}$ While most of our services remained, some high-risk procedures such as endotracheal intubation during general anaesthesia ${ }^{3,4}$ and non-contact tonometry ${ }^{5}$ which generates aerosols have been significantly curtailed or suspended for this period. ${ }^{6}$ Substantiated concerns have been raised for intraocular surgeries 
involving high-speed instruments such as phacoemulsification. ${ }^{7}$ It is the most commonly performed surgery at our center. The potential of intraoperative aerosolization during the application of ultrasound energy might lead to viral transmission. ${ }^{8}$

We previously published our findings from video assessment of phacoemulsification in model eyes that aerosols could be generated during phacoemulsification. ${ }^{9}$ Other groups have also demonstrated similar findings in porcine eyes and goat eyes mounted with human cadaveric corneoscleral rim. ${ }^{10-12}$ However, these studies were all conducted in a simulated setting, while confirmatory studies of phacoemulsification in real-world settings have yet to be conducted. The living human cornea biomechanics also differs from plastic model eyes and cadaveric eyes. Therefore, it is still uncertain whether aerosolization occurs, and to what extent, during routine phacoemulsification in actual patients.

The aims of this study are to evaluate the extent of visible aerosolization and fluid spillage during different stages of phacoemulsification in a real-world clinical setting, and any potential risk factors which may be associated with the generation of visible aerosols and fluid droplets.

\section{Methods}

This is a prospective interventional case series of consecutive human subjects. Thirty-one consecutive patients undergoing routine, elective phacoemulsification and intraocular lens implantation in Lo Fong Shiu Po Eye Center at Grantham Hospital (Wong Chuk Hang, Hong Kong) by 3 board-certified specialists in ophthalmology (JW, JK, JC; first 3 authors) were recruited to this study during 29th July to 28th August 2020. Written informed consents for the study were obtained from all subjects before the surgery with the purposes and details of the study thoroughly explained. The study was approved by the Institutional Review Board of the University of Hong Kong and Hospital Authority Hong Kong West cluster (HKU/HA HKW IRB) and was conducted in accordance with the Declaration of Helsinki.

The cataract surgeries were all performed under topical anesthesia with anesthetic eye drops. Balanced-salt solution (BSS) or xylocaine gel was used for intraoperative cornea lubrication, according to surgeons' preferences. Clear corneal incision was made superiorly or temporally, using a $2.2 \mathrm{~mm}$ or $2.8 \mathrm{~mm}$ double-bevel disposable keratome depending on the size of the phacoemulsification probe sleeve used. Paracentesis were made 90 degrees to the main wound for secondary instruments, using a disposable 15-degree metal blade. Either 1 or 2 paracenteses were made depending on whether the surgeons used coaxial or bimanual instruments for the irrigation/aspiration step. Anterior chamber was maintained by intracameral injection of ophthalmic viscosurgical device (OVD) and capsulorhexis were made. Centurion Vision System (Alcon Laboratories, Inc.) was used to perform the phacoemulsification procedures. Stop-and-chop technique was used to fragment the nucleus of cataract. The nuclear fragments were aspirated with the probe and the remaining cortical matters were removed using coaxial or bimanual irrigation/aspiration instruments. The intraocular lens was implanted after the capsular bag had been distended by OVD. The OVD was removed completely by irrigation/ aspiration instruments afterwards and the wounds were sealed by hydrating the corneal stroma with BSS. Intracameral antibiotics were given at the end of the surgery.

Two methods were employed to detect the presence of aerosolization during the surgical procedures. First, a fullframe (36mm CMOS sensor) digital camera (Alpha 7III, Sony) with a 28-70mm F3.6-5.6 lens (SEL2870, Sony) was set up from the side, near the surgical field, to capture a $4 \mathrm{~K}$ high-definition, 120 frame-per-second (fps) video of the entire surgical procedure with the exposure and focus optimized. Each of the surgical videos was evaluated by 2 independent and masked assessors (author KS and JL) afterwards to determine if aerosols were generated during the whole surgical process, from wound creation, capsulorhexis, nuclear fragmentation and aspiration, cortex removal, intraocular lens implantation, irrigation/aspiration, to stromal hydrations of the wounds. If discrepancies existed between the 2 assessors, they reviewed the video again together and come up with a final assessment result. A prior validation test with the same camera set-up demonstrating deliberate aerosol generation using the phacoemulsification probe was conducted to ensure our settings could effectively capture aerosols. Figure 1 shows a snapshot of the video demonstrating aerosolization and fluid droplet productions at the tip of phacoemulsification probe.

Second, a 15 × $25 \mathrm{~cm}$ water-contact indicator tape (3M) which turns from white to red at contact with fluid was mounted at the base of the operating microscope (Figure 2), at the level of, and surrounding, the objective lens, close to the surgical field (around $15 \mathrm{~cm}$ above patient's eye) to detect the presence of any water contact. A round hole of $8 \mathrm{~cm}$ in diameter was made in the water-contact indicator tape to allow the microscope to operate as normal. The plastic film on the watercontact indicator tape was removed to enhance contact sensitivity (Figure 3A). As the color of the water-contact indicator 


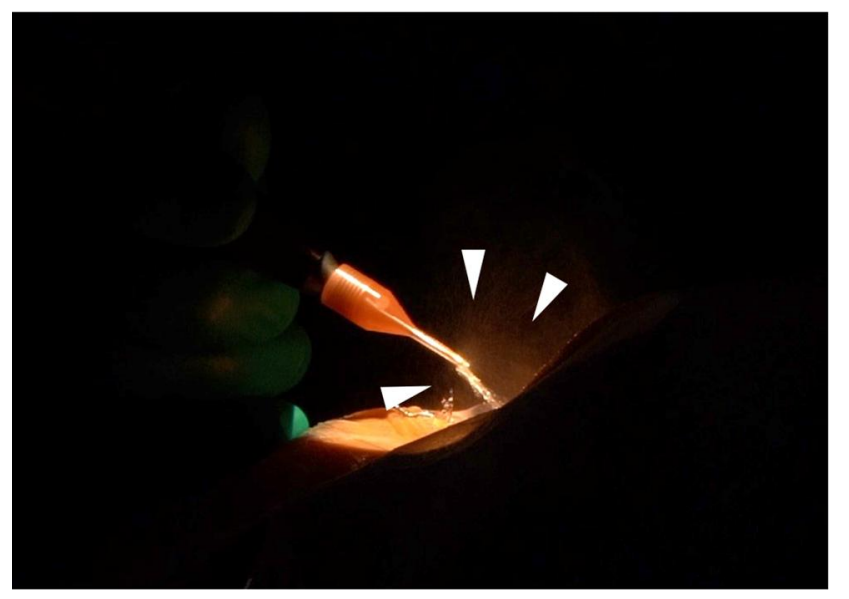

Figure I Snapshot in the video demonstrating aerosol generated at the tip of phacoemulsification probe. White arrows indicate aerosols generated.

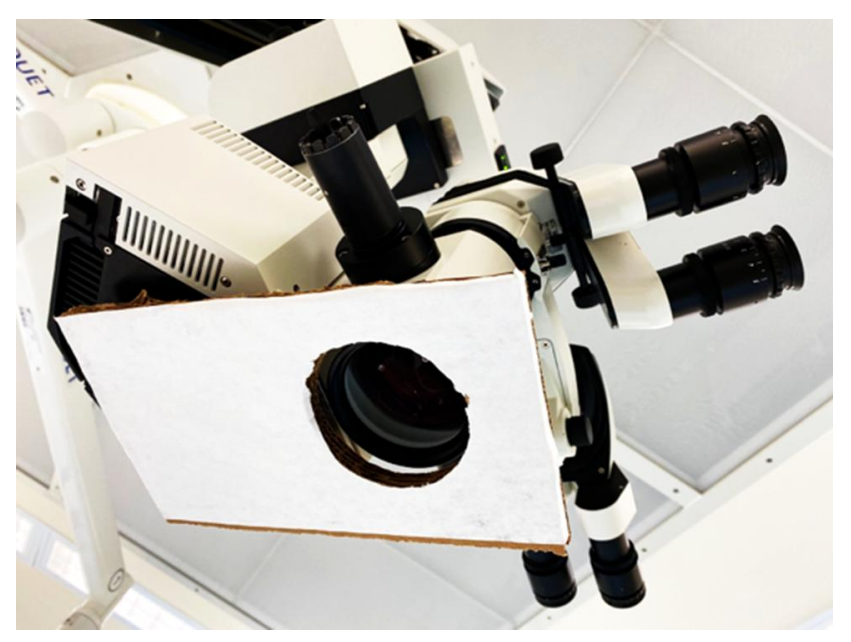

Figure 2 Water-contact indicator tape of $15 \times 25 \mathrm{~cm}$ with an $8 \mathrm{~cm}$ diameter hole was mounted on the surgical microscope to detect aerosol contact.

tape would change from white to red, presence of red spots on the tape would be indicative of fluid contact during the surgery. To confirm that this method was sensitive in detecting aerosols, we turned on the phacoemulsification machine (Centurion Vision System, Alcon Laboratories, Inc.) for 5 seconds while placing the water indicator tape at $10 \mathrm{~cm}$ distance from the probe of the machine. Multiple red dots were seen on the tape after deliberately generating aerosols from the probe (Figure 3B). Droplets of fluid were splashed towards the tape to demonstrate red marks indicating water contact (Figure 3C).

Other clinical information and data, including the basic demographics of the subjects, the nuclear densities of their cataracts, wound constructions, operation durations, and other surgical details were documented. Descriptive statistics were used to present non-comparative data. Analyses were conducted to identify possible associations between the presence of aerosol or droplet generation and these various factors. Chi-square test was used for categorical data such as wound location and coaxial versus bimanual irrigation/aspiration. Mann-Whitney- $U$ test was used for continuous data such as age of subject and surgical time. An alpha level of 0.05 was used for statistical significance.

\section{Results}

A total of 31 eyes from 31 patients were recruited. One subject was excluded from the study because of posterior capsular rupture during the surgery. The other 30 subjects underwent uneventful phacoemulsification and intraocular lens implantation. Table 1 summarizes the demographics of the subjects, information of the cataracts, and the surgical procedure details.

In all 30 subjects included for analysis, none have visible aerosols generated or fluid contact detected during phacoemulsification nor the entire surgery on video analyses and water-contact indicator tape assessments, respectively. During the video assessment by the independent assessors, large fluid droplets were found generated from the paracentesis wound with the chopping instrument in $70 \%$ of the cases (21 of the 30 subjects) during surgery (Figure 4). None of these droplets reached the watercontact indicating tape. Table 2 summarizes the findings.

Chi-square tests and Mann-Whitney- $U$ tests were conducted to examine the associations between the presence of droplets production during the surgery and the age and gender of the patient, laterality of the operated eye, nuclear density of the cataract, surgical time, wound position, wound size, irrigation/aspiration method, and the surgeon. None of these factors were found to be associated with the presence of droplets production during the surgery. Table 3 summarizes the statistical analysis.

\section{Discussions}

With a confirmed case of COVID-19 re-infection reported earlier in Hong Kong, ${ }^{13}$ it is highly probable that the pandemic will be with us for a much longer duration than we had originally anticipated, short of an effective vaccine being available. As the battle against this pandemic may be prolonged, it is important to maintain certain crucial healthcare services, especially in the public sector. In Hong Kong, the vast majority of our population relies on public healthcare services. Patients would usually have to wait for more than 1 year to have cataract surgeries in public hospitals. ${ }^{14}$ Although recent publication has suggested phacoemulsification can generate aerosols in simulated settings ${ }^{12}$ and raised 


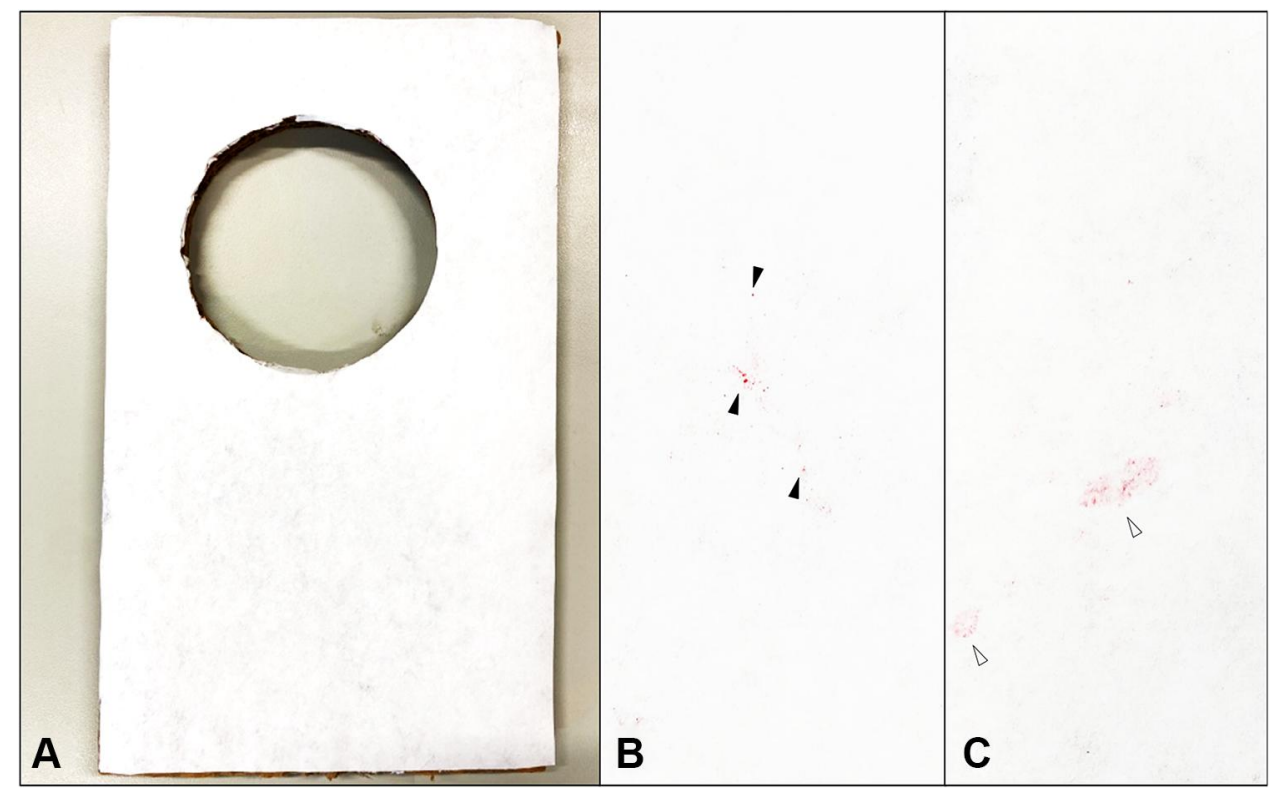

Figure 3 (A) Water-contact indicator tape without any previous water contact. (B) Water-contact indicator tape after exposing to aerosols generated from phacoemulsification machines. Solid triangles showing presence of red-dots after aerosol contacts. (C) Water-contact indicator tape after splashing with fluid drops. White triangles showing red areas on the tape after droplet contacts.

concerns on the potential spread of COVID-19 intraoperatively, suspending cataract surgeries would substantially increase our already long waiting time, and overload subsequent ophthalmic services after the pandemic.

In our earlier model eye experiment, ${ }^{9}$ we found that higher ultrasound energy use during phacoemulsification was associated with greater aerosolization, especially when the tip of the probe is pulled back closer to the wound or outside the eye entirely. Similar findings were observed in the study conducted by Shetty et al, ${ }^{11}$ in which nucleated goat's eyes and cadaveric human corneoscleral rims mounted on artificial anterior chambers were both used for in-intro experiments. The authors used highspeed camera with shadowgraphy technique to visualize aerosols and no aerosolization was detected in closed chambers but it did present when the probe is exposed. In contrast, Lee et al found that aerosolization phenomena were similar under various phacoemulsification settings in their porcine eye experiments. Therefore, we conducted this study to ascertain the likelihood of aerosolization during phacoemulsification in a real-world setting.

Of the 30 cases in this study, none had aerosolization during the entire surgical procedure. Our results showed that the chance of aerosolization during routine, uncomplicated phacoemulsification is less than 1 in 30 , or $<3.33 \%$. This suggested that aerosolization may be very uncommon in routine uncomplicated phacoemulsifications, where the risks of viral spread by aerosolization are expected to be low. In our study, the recruited subjects included surgeries performed by 3 different surgeons, using a variety of wound sizes and positions, means of intraoperative ocular surface lubrication, and in cataracts of different nuclear densities. Our findings suggest that the likelihood of aerosolization during phacoemulsification remains low, irrespective of these factors. The subjects were recruited consecutively to avoid selection bias.

The methods of aerosol evaluation, namely the $120 \mathrm{fps}$ high-resolution videos and the water-contact indicator tape, were not without their own limitations. Unlike shadowgraphy technique using high-speed cameras, it did not allow us to measure the travelling distances of the aerosols and fluid droplets. It is difficult to quantify the smallest particle size the camera could capture either. Small particles could be missed by the camera. Attempts were made to capture aerosols using a high-speed camera (S-PRI, AOS Technologies AG) with up to $1000 \mathrm{fps}$ capturing rate for better aerosol imaging, like what our group has done in a previous study using model eye. ${ }^{9}$ However, this required very intense lighting to enable imaging the aerosols clearly, despite using lens of different specifications, including $25 \mathrm{~mm} / \mathrm{F} 2.8$ lens (Venus Optics, China) to $35 \mathrm{~mm} / \mathrm{F} 1.8$ lens (Sony, Japan), or reducing the rate of capture. In fact, in our earlier model eye experiments, a LED surgical lamp was required to illuminate the 
Table I Subject Demographics, Information of the Cataracts and the Surgical Procedure Details

\begin{tabular}{|c|c|c|c|c|}
\hline & $\begin{array}{l}\text { All } \\
\text { Subjects }\end{array}$ & $\begin{array}{l}\text { Surgeon } \\
\text { I }\end{array}$ & $\begin{array}{l}\text { Surgeon } \\
2\end{array}$ & $\begin{array}{l}\text { Surgeon } \\
3\end{array}$ \\
\hline Number of subjects & 30 & 14 & & \\
\hline Mean Age & $72.10 \pm$ & $71.79 \pm$ & $73.40 \pm$ & $70.67 \pm$ \\
\hline & 9.34 & 10.30 & 10.33 & 5.68 \\
\hline \multicolumn{5}{|l|}{ Gender } \\
\hline Male & 10 & 5 & 1 & 4 \\
\hline Female & 20 & 9 & 9 & 2 \\
\hline \multicolumn{5}{|l|}{ Laterality } \\
\hline Right & 10 & 3 & 5 & 2 \\
\hline Left & 20 & 11 & 5 & 4 \\
\hline \multicolumn{5}{|l|}{ Nuclear sclerosis grading } \\
\hline \multirow[t]{2}{*}{ Mean \pm SD } & $1.63 \pm$ & $1.71 \pm$ & $1.60 \pm$ & $1.50 \pm$ \\
\hline & 0.67 & 0.61 & 0.70 & 0.84 \\
\hline Grade I & 14 & 5 & 5 & 4 \\
\hline Grade 2 & 13 & 8 & 4 & I \\
\hline Grade 3 & 3 & I & 1 & 1 \\
\hline Grade 4 & 0 & 0 & 0 & 0 \\
\hline \multicolumn{5}{|l|}{ Mean duration $(\min )$} \\
\hline \multirow[t]{2}{*}{ Total surgical time } & $17.40 \pm$ & $16.07 \pm$ & $17.70 \pm$ & $20.00 \pm$ \\
\hline & 4.58 & 4.73 & 5.08 & 1.90 \\
\hline \multicolumn{5}{|l|}{ Cornea wound size } \\
\hline $2.2 \mathrm{~mm}$ & 20 & 14 & 0 & 6 \\
\hline $2.8 \mathrm{~mm}$ & 10 & 0 & 10 & 0 \\
\hline \multicolumn{5}{|l|}{ Cornea wound position } \\
\hline Temporal & 28 & 13 & 10 & 5 \\
\hline Superior & 2 & 1 & 0 & 1 \\
\hline \multirow{2}{*}{\multicolumn{5}{|c|}{$\begin{array}{l}\text { Mode of irrigation/ } \\
\text { aspiration }\end{array}$}} \\
\hline & & & & \\
\hline Bimanual & 20 & 14 & 0 & 6 \\
\hline Coaxial & 10 & 0 & 10 & 0 \\
\hline \multirow{2}{*}{\multicolumn{5}{|c|}{$\begin{array}{l}\text { Intraoperative corneal } \\
\text { lubrication }\end{array}$}} \\
\hline & & & & \\
\hline Balanced salt solution & 16 & 0 & 10 & 6 \\
\hline Xylocaine gel & 14 & 14 & 0 & 0 \\
\hline
\end{tabular}

Abbreviation: SD, Standard Deviation.

imaging field, similar to the illumination setting described by Shetty et al, ${ }^{11}$ which would not be possible in realworld surgical settings. We, therefore, use a full-frame digital camera with capacity of recording 120fps 4Kresolution videos. Camera settings were adjusted and optimized before recording for each surgery.

For the water-contact indicator tape method for evaluating aerosols, we were inspired by the small piece of paper used inside mobile phones to indicate if the phones had been damaged by water. In fact, the water-contact indicator tape we used is the same material used inside mobile phones. We have reviewed the literature and did

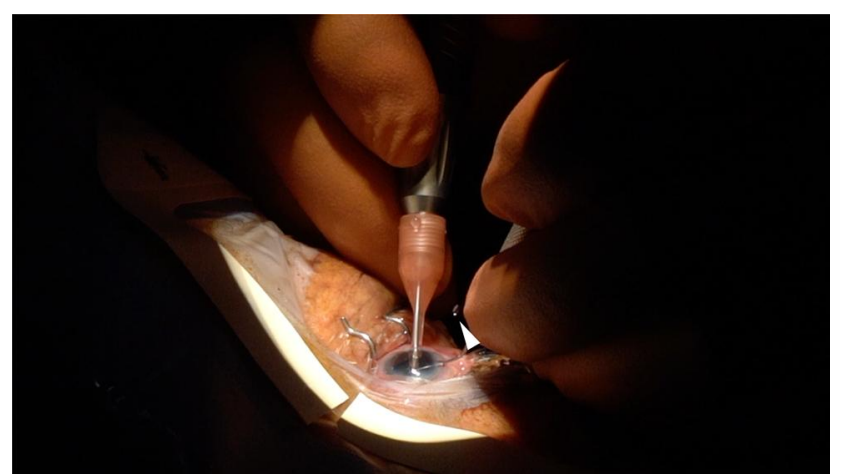

Figure 4 Snapshot of one of the surgical videos showing droplets spilling from the paracentesis wound during chopping maneuver. White arrows indicate the fluid droplet.

not find any similar use of the material before. The front surface of the tape was white. Once there is water contact, the corresponding area will turn red permanently. There was a protective transparent plastic film on the front side of the tape to avoid ambient moist damage. We removed this protective film before the start of the experiment to allow more sensitivity in detecting small aerosols.

In order to make sure the evaluations were valid, we tested these 2 evaluation methods for their effectiveness in detecting aerosols prior to our actual studies. We deliberately produced aerosols and fluid drops using the same phacoemulsification machine at a close distance to the tape and also used the same video camera to capture them under the usual surgical lighting. The assessments were completed independently by 2 ophthalmologists who were masked from the patients' and surgeons' information. Only when they have discrepancies would they review the videos together again and came up with a final decision.

We limited the surgeons in our study to 3 experienced cataract surgeons only. All three of our surgeons are board-certified ophthalmologists who have performed at least 1000 phacoemulsification procedures. This avoids introducing additional confounders associated with surgical trainees who may have widely varying level of experience and surgical competence, limiting the generalization of our findings to most clinical practices. However, this also implies that our findings may not reflect the overall likelihood of intraoperative aerosolization across ophthalmologists of varying competencies.

The probable reasons why our findings in real-world settings differ from earlier work in simulated settings could be that ultrasound energy used in real patients might not be as high as in simulated settings, and we usually only apply ultrasound 
Table 2 Results of Video and Water-Contact Indicator Tape Evaluations for Aerosol and Droplet Detections

\begin{tabular}{|l|l|l|l|l|}
\hline & All Subjects & Surgeon I & Surgeon 2 & Surgeon 3 \\
\hline Number of subjects & 30 & 14 & 10 & 6 \\
\hline $\begin{array}{l}\text { Aerosol detected during surgery } \\
\text { By video } \\
\text { By water-contact indicator tape }\end{array}$ & 0 & 0 & 0 & 0 \\
\hline $\begin{array}{l}\text { Droplets detected during surgery } \\
\text { By video } \\
\text { By water-contact indicator tape }\end{array}$ & $21(70 \%)$ & 0 & 0 & 0 \\
\hline
\end{tabular}

Table 3 Results of Statistical Testing for the Associations Between Various Factors and the Presence of Large Droplet Spillage from the Paracentesis Wounds

\begin{tabular}{|l|l|l|l|}
\hline Factors Analysed & Statistical Test Used & Chi-Square Value/Z-Score & p-value \\
\hline Surgeon & Chi-square & 1.63 & 0.44 \\
Age of subject & Mann-Whitney-U & 0.66 & $0.5 \mathrm{I}$ \\
Gender of subject & Chi-square & 0 & 1.00 \\
Laterality of operated eye & Chi-square & 0.71 & 0.40 \\
Wound size (2.2mm vs 2.8mm) & Chi-square & 0.71 & 0.40 \\
Wound position (superior vs temporal) & Chi-square & 0.92 & 0.34 \\
Coaxial vs bimanual irrigation/aspiration & Chi-square & 0.71 & 0.40 \\
Nuclear density of cataract & Chi-square & 1.51 & 0.47 \\
Surgical time & Mann-Whitney-U & 1.15 & 0.25 \\
\hline
\end{tabular}

energy only when tackling the nucleus of the lens, which is far away from the corneal wound. Furthermore, the living corneal tissue could be more elastic than cadaveric tissue, and hence the corneal wound might seal more tightly to the ultrasound probe, reducing the chance of aerosol leak during phacoemulsification.

On the other hand, we found that in $70 \%$ of the cases there were large droplets spilled from the paracentesis wound during surgery. This observation has not been reported in earlier studies, likely because in simulated settings incisions were only made for the phacoemulsification probe but not the paracentesis for the chopping instruments. $^{9,11}$ Despite droplet spillage being common in our study, the spilling distances are short and did not reach the water-indicator tape placed around $15 \mathrm{~cm}$ away from the operating eye. It is unlikely that these droplets would spill out of the surgical field if these large droplets could not even reach the water-contact indicating tape. Further studies might be valuable to evaluate the extent of this droplet-spilling phenomenon and the resultant risks of disease transmissions. In spite of the fact that none of the factors in Table 3 were found to be statistically significantly associated with the fluid spillage, we could not confidently say that there were no genuine associations because of the limited sample size of our study.
In conclusion, this study demonstrated that no visible aerosolization was detected during phacoemulsification on patients performed by experienced surgeons. Therefore, it would be reasonably safe, especially if already using standard personal protective equipment in all clinical settings, to continue to provide much needed cataract surgeries for our patients during the COVID-19 pandemic.

\section{Disclosure}

The authors report no conflicts of interest in this work.

\section{References}

1. Weekly Epidemiological Update. World Health Organization; December 8, 2020. Available from: https://www.who.int/publications/ $\mathrm{m} /$ item/weekly-epidemiological-update-8-december-2020. Accessed December 8, 2020.

2. Shih KC, Wong JKW, Lai JSM, Chan JCH. The case for continuing elective cataract surgery during the COVID-19 pandemic. $J$ Cataract Refract Surg. 2020;46(6):921. doi:10.1097/j.jcrs.0000000000000225

3. Fowler RA, Guest CB, Lapinsky SE, et al. Transmission of severe acute respiratory syndrome during intubation and mechanical ventilation. Am J Respir Crit Care Med. 2004;169(11):1198-1202. doi:10.1164/rccm.200305-715OC

4. Tran K, Cimon K, Severn M, Pessoa-Silva CL, Conly J. Aerosol generating procedures and risk of transmission of acute respiratory infections to healthcare workers: a systematic review. PLoS One. 2012;7(4):e35797. doi:10.1371/journal.pone.0035797 
5. Britt JM, Clifton BC, Barnebey HS, Mills RP. Microaerosol formation in noncontact 'air-puff' tonometry. Arch Ophthalmol. 1991;109 (2):225-228. doi:10.1001/archopht.1991.01080020071046

6. Lai THT, Tang EWH, Chau SKY, Fung KSC, Li KKW. Stepping up infection control measures in ophthalmology during the novel coronavirus outbreak: an experience from Hong Kong. Graefes Arch Clin Exp Ophthalmol. 2020;258(5):1049-1055. doi:10.1007/s00417-02004641-8

7. Chandra A, Haynes R, Burdon M, et al. Personal protective equipment (PPE) for vitreoretinal surgery during COVID-19. Eye (Lond). 2020;34(7):1196-1199. doi:10.1038/s41433-020-0948-3

8. van Doremalen N, Bushmaker T, Morris DH, et al. Aerosol and surface stability of SARS-CoV-2 as compared with SARS-CoV-1. $N$ Engl J Med. 2020;382(16):1564-1567. doi:10.1056/ NEJMc2004973

9. Kwok J, Chan JCH, Wong JKW, Lai JSM. Videographic evaluation of aerosol generation during cataract surgery. $J$ Cataract Refract Surg. 2020;46(12):1683-1684. doi:10.1097/j.jcrs.0000000000000312
10. Lee H, Naveed H, Ashena Z, Nanavaty MA. Aerosol generation through phacoemulsification. $J$ Cataract Refract Surg. 2020;46 (9):1290-1296. doi:10.1097/j.jcrs.0000000000000288

11. Shetty N, Kaweri L, Khamar P, et al. Propensity and quantification of aerosol and droplet creation during phacoemulsification with high-speed shadowgraphy amid COVID-19 pandemic. $J$ Cataract Refract Surg. 2020;46(9):1297-1301. doi:10.1097/j. jcrs.0000000000000289

12. Koshy ZR, Dickie D. Aerosol generation from high speed ophthalmic instrumentation and the risk of contamination from SARS COVID19. Eye (Lond). 2020;34(11):1954-1955. doi:10.1038/s41433-020-1000-3

13. Parry J. Covid-19: hong Kong scientists report first confirmed case of reinfection. BMJ. 2020;370:m3340. doi:10.1136/bmj.m3340

14. Hospital authority service guides - elective cataract surgery. Available from: https://www.ha.org.hk/visitor/ha_visitor_index.asp?Content_ $\mathrm{ID}=214184 \&$ Lang $=$ ENG\&Dimension $=100 \&$ Parent $\mathrm{ID}=214172$. Accessed September 7, 2020.
Clinical Ophthalmology

\section{Publish your work in this journal}

Clinical Ophthalmology is an international, peer-reviewed journal covering all subspecialties within ophthalmology. Key topics include: Optometry; Visual science; Pharmacology and drug therapy in eye diseases; Basic Sciences; Primary and Secondary eye care; Patient Safety and Quality of Care Improvements. This journal is indexed on PubMed

Submit your manuscript here: https://www.dovepress.com/clinical-ophthalmology-journal
Dovepress

Central and CAS, and is the official journal of The Society of Clinical Ophthalmology (SCO). The manuscript management system is completely online and includes a very quick and fair peer-review system, which is all easy to use. Visit http://www.dovepress.com/ testimonials.php to read real quotes from published authors. 